\title{
Combustion and Emission Characteristics of a Diesel Engine Operating with Varying Equivalence Ratio and Compression Ratio - A CFD Simulation
}

\author{
Kazi Mostafijur Rahman* and Zobair Ahmed \\ Department of Mechanical Engineering, Khulna University of Engineering \& Technology, Khulna-9203, BANGLADESH
}

Received: September 19, 2020, Revised: October 03, 2020, Accepted: October 04, 2020, Available Online: October 05, 2020

\begin{abstract}
The performance of diesel engine highly depends on atomization, vaporization and mixing of fuel with air. These factors are strongly influenced by various parameters e.g. injection pressure, injection timing, compression ratio, equivalence ratio, cylinder geometry, in cylinder air motion etc. In this study, a diesel engine has been investigated by employing a commercial CFD software (ANSYS Forte, version 18.1) especially developed for internal combustion engines (ICE) modeling; focusing primarily on the effects of equivalence ratio and compression ratio on combustion and emission characteristics. RNG k- $\varepsilon$ model was employed as the turbulence model for analyzing the physical phenomena involved in the change of kinetic energy. In order to reduce the computational cost and time, a sector mesh of 450 angle with periodic boundary conditions applied at the periodic faces of the sector, is considered instead of using the whole engine geometry. Simulations are performed for a range of equivalence ratio varying from 0.6 to 1.2 and for three compression ratios namely, 15:1, 18:1 and 21:1. Results show that, improvement in combustion characteristics with higher compression ratio could be achieved for both lean and rich mixtures. Peak in-cylinder pressure and peak heat release nearer to TDC are achieved for compression ratio of 18:1 that could results in more engine torque. For compression ratio beyond 16:1, effects of fuel concentration on ignition delay is more pronounced. At lower compression ratio, in-cylinder temperature is not sufficiently high for atomization, vaporization, mixing of fuel with air, and preflame reactions to occur immediately after the fuel injection. NOx emission in diesel engine increases due to higher pressure and temperature inside the cylinder associated with relatively higher compression ratio. Rich mixture leads to more $\mathrm{CO}$ and unburnt hydrocarbon emission compared to lean mixture as result of incomplete combustion. Engine operation with too high compression ratio is detrimental as emission is a major concern.
\end{abstract}

Keywords: Computational Fluid Dynamics (CFD), Diesel engine, Compression ratio, Combustion performance, Engine emissions.

This work is licensed under a Creative Commons Attribution-Non Commercial 4.0 International

\section{Introduction}

Due to limited reserve of petroleum, ever increasing energy demand and stringent emissions legislation; automakers are striving to develop advanced engine with improved the fuel economy, reduced emissions and higher thermal efficiency. Diesel engine is a high compression ratio internal combustion engine where auto-ignition of fuel occurs due to high temperature developed in the compression stroke. Diesel engine combustion is considered as the series of complex processes and the main events are categorized into ignition delay, uncontrolled rapid combustion phase, mixing controlled combustion phase and after burning phase. The time interval between start of fuel injection and start of combustion refers to ignition delay. This delay period can further be divided into two parts - Physical delay and chemical delay. The fuel, accumulated during physical and chemical delay, is burnt rapidly causing very high heat release in uncontrolled combustion phase. After that the burning rate is controlled by the rate of fuel injection and mixing of fuel with the surrounding air, in controlled combustion phase. After burning phase involves lower rate of heat release due to combustion of remaining fuel [1]. In transportation sector, diesel engine is preferred over petrol engine because of its higher thermal efficiency, better fuel economy and higher engine power and torque. However, they suffer from excessive emissions which require the use of expensive exhaust-gas after-treatment devices [2]. The emission products include soot particles, oxides of nitrogen (NOx), carbon monoxides (CO), unburnt hydrocarbons (UHC) and particulate matters (PM) [3]-[6]. Due to the incomplete combustion of fuel unburnt hydrocarbon (UHC) and carbon monoxides (CO) are generated. The amount of $\mathrm{NO}_{\mathrm{x}}$ particles, soot products and other undesired gases in the exhaust gas could be higher than the gasoline engine.

In recent years, extensive researches on diesel engines are ongoing aiming to reduce NOx and soot emission without compromising higher thermal efficiency of the engine. In a study by Reitz et al. [7], the effects of EGR, equivalence ratio and mixing timing on emission levels for heavy duty Premixed Charge Compression Ignition (PCCI) engine has been analysed. At high EGR percentage, drastic reduction in PM levels is reported. Intake temperature is increased with high EGR rate which reduces the PM level. The emissions of PM, NOx and HC are reduced and emission of $\mathrm{CO}$ is increased with the increase of mixing timing. As mixing time increases, the charge (fuel-air) becomes more homogeneous and thus reduces emissions. The emission of PM is the function of in-cylinder average equivalence ratio. It is seen that at lean equivalence ratio, PM is not formed. Jindal et al. [8] investigated the effect of compression ratio and injection pressure in a direct injection diesel engine running on jatropha methyl ester. Being a fuel of different origin, the standard design parameters of diesel engine may not be suitable. For small size direct injection constant pressure engine, optimum combination of emission is found at CR 18 with injection pressure of 250 bars. Raheman et al. [9] 
studied the performance of Richardo E6 engine using biodiesel obtained from mahua oil (B100) and its blend with high speed diesel (HSD) at varying compression ratio (CR), injection timing and engine loading. Brake specific fuel consumption (bsfc) and exhaust gas temperature increases, whereas brake thermal efficiency decreases with the increase in proportion of biodiesel in the blends at all compression ratios (18:1 to 20:1) and injection timings $\left(35-45^{\circ}\right.$ before TDC). Effect of equivalence ratio on combustion and emissions with a low compression ratio of 14.2 in a dual-fual 6-cylinder engine was investigated experimentally by Jinbao et al. [10]. They reported that the gas consumption rate decreases with the increase of equivalence ratio regardless of strategy in nozzle parameter, exhaust gas recirculation (EGR) rate, injection parameter. Peak heat release rate and exhaust gas temperature increased whereas combustion duration decreased due to the high equivalence ratio in dual fuel ignition mode. Juan et al. [11] studied the knocking tendency in a Cooperative Fuel Research (CFR) engine due to the effect of the varying equivalence ratio. They reported that lean mixture reduces the knocking tendency allowing to operate the CFR engine at higher critical compression ratio. Dong Nam [12] carried out postgraduate research on reducing engine emissions (NOx) from marine diesel engines. He concluded that NOx emission can be reduced by primary methods such as retard injection, fuel nozzle modification, change of compression ratio, water direct injection, water emulsification, exhaust gas recirculation (EGR) and secondary method such as selective catalytic reduction (SCR). Jafarmadar [13] worked on NOx reduction by split injection. In diesel engine, to gain reduction in NOx emission without increasing soot emission is very difficult by adjusting injection timing only. This study demonstrated that split injection could be a promising technique to reduce both NOx and soot emission simultaneously. Recently, numerical simulation of ICE through Computational Fluid Dynamics (CFD) modelling, has become a promising tool to get better insight about the complex processes such as fuel injection, spray formation, chemical kinetics, ignition model, flame propagation, knock phenomena, emission formations that occur inside the cylinder of ICE. Taqizadeh et al. [14] performed numerical investigation of effects of equivalence ratio on combustion characteristics of an RCCI engine. They found that, by increasing equivalence ratio from 0.35 to 0.55 in a constant energy ratio, noticeable growth in the maximum amount of pressure and temperature could be achieved; consequently, NOx emission would increase significantly, IMEP increases by $43 \%$, and ISFC decreases by $30 \%$.

Though many experimental investigations are reported so far, but only a few computational fluid dynamic studies on diesel engines are available in the literature. Therefore, in the present study, effects of equivalence ratio and compression ratio on combustion and emission characteristics in a diesel engine have been investigated through computational fluid dynamics (CFD) modelling.

\section{Computational approach}

ANSYS FORTE, version 18.1, has been used in this numerical study of diesel engine operating with varying equivalence ratio and compression ratio. This is a fluid-dynamics software that specializes in the simulation of combustion processes in an internal combustion engine, using a highly efficient coupling of detailed chemical kinetics, liquid fuel spray and turbulent gas dynamics. The software solves the full Reynolds-averaged Navier-Stokes (RANS) equations with well- established flow turbulence models. RNG k- $\varepsilon$ model was employed as the turbulence model for analyzing the physical phenomena involved in the change of kinetic energy.

\subsection{Basic governing equations}

The working fluids for internal combustion engines are airfuel mixture before combustion and the burned products after combustion. Basic fluid dynamics are governed by the NavierStokes equation in the turbulent reacting flows. Governing equations are mainly derived by-

- Assuming ideal gas law for gas phase

- The use of Fick's law for mass diffusion

- Assuming Newtonian fluid

- The use of Fourier's law for thermal diffusion

2.1.1 Species conservation equation

$$
\begin{aligned}
\frac{\partial \bar{\rho}_{k}}{\partial t}+\nabla\left(\bar{\rho}_{k} \tilde{u}\right)= & \nabla\left[\bar{\rho}_{k} D \bar{y}_{k}\right]+\nabla \varphi+\bar{\rho}_{k}^{c} \\
& +\bar{\rho}_{k}^{s} \quad(\text { Here }, k=1,2, \ldots K)
\end{aligned}
$$

Here, $\rho$ is the density, subscript $\mathrm{k}$ means species index, $\mathrm{K}$ is the total number of species, $u$ is the flow velocity vector

The term $\varphi$ accounts for the effects for the ensembleaveraging the convection term i.e.

$$
\varphi=\bar{\rho}_{k} \tilde{u}-\overline{\rho_{k} u}
$$

$\bar{\rho}_{k}^{c}$ and $\bar{\rho}_{k}^{s}$ are terms due to chemical reactions and spray evaporation, respectively.

\subsubsection{Fluid continuity equation}

The continuity equation fir the total gas phase fluid is,

$$
\frac{\partial \bar{\rho}}{\partial t}+\nabla(\bar{\rho} \tilde{u})=\overline{\rho^{s}}
$$

\subsubsection{Momentum conservation equation}

The momentum equation considering the effects of convection, pressure force, viscous stress and turbulent transport as well as the impact from liquid sprays and body force is,

$$
\frac{\partial \bar{\rho} \tilde{u}}{\partial t}+\nabla(\bar{\rho} \tilde{u} \tilde{u})=-\nabla \bar{p}+\nabla \bar{\sigma}-\frac{2}{3} \bar{\rho} \widetilde{k} I+\bar{F}^{S}+\bar{\rho} \bar{g}
$$

where, $\mathrm{p}$ is the pressure, $\bar{F}^{S}$ is the the rate of momentum gain per unit volume due to the spray, $\bar{g}$ is the specific body force, $\bar{\sigma}$ is the viscous shear stress, $\bar{\sigma}=\bar{\rho} v\left[\nabla \tilde{u}+(\nabla \tilde{u})^{T}-\frac{2}{3}(\nabla \tilde{u}) I\right]$

$\mathrm{V}=$ laminar kinetic velocity, $\mathrm{I}=$ identity tensor, superscript $\mathrm{T}$ means transpose of a tensor.

The stress accounts for the effects for ensemble averaging of filtering of the nonlinear convection term i.e. $\Gamma=\bar{\rho}(\widetilde{u u}-$ $\tilde{u} \tilde{u})$. In the RANS approach it is called Reynolds Stress.

\subsubsection{Energy conservation equation}

Based on First Law of Thermodynamics, the change of internal energy has to be balanced by the pressure work and heat transfer. The internal energy transport equation is.

$$
\begin{aligned}
\frac{\partial \bar{\rho} \tilde{I}}{\partial t}+\nabla(\bar{\rho} \tilde{u} \tilde{I})= & -\bar{\rho} \nabla \tilde{u}-\bar{p} \nabla \tilde{u}-\nabla \tilde{J}-\nabla H+\bar{\rho} \tilde{\varepsilon}+\bar{Q}^{C} \\
& +\bar{Q}^{s}
\end{aligned}
$$


where, $I$ is the specific internal energy, $\mathrm{J}$ is the heat flux vector, $\tilde{J}=-\lambda \nabla \tilde{T}-\bar{\rho} D_{T} \sum_{k} \bar{h}_{k} \nabla\left(\frac{\bar{\rho}_{k}}{\rho}\right)$

$\lambda$ is the thermal conductivity, which is related to the thermal diffusivity $\alpha$ and heat capacity $C_{p}$ by $\lambda=\bar{\rho} \mathrm{C}_{\mathrm{p}} \alpha, \mathrm{T}$ is the temperature and $\bar{h}_{k}$ is the specific enthalpy of species k. $\tilde{\varepsilon}$ is the dissipation rate due to chemical heat release and spray interactions, respectively.

The term $\mathrm{H}$ accounts for the effects of ensemble averaging or filtering of the convection term, i.e. $H=\bar{\rho}(\widetilde{u I}-\tilde{u} \tilde{I})$

\subsubsection{Reynolds averaged navier stokes (RANS) approach}

The aim of the RANS is to simulate ensemble-average flow field. The ensemble average is an average that allows the interpretation of the phenomena in terms of the repeatability of multi-component flows.

To model the turbulent transport process gradient-diffusion assumptions are approached. For momentum equation, the deviatoric components of the Reynolds stress are assumed to be proportional to the mean deviatoric rate of strain. The Reynolds stress tensor is,

$$
\Gamma=-\bar{\rho} \vartheta_{T}\left[\nabla \tilde{u}(\nabla \tilde{u})^{T}-\frac{2}{3}(\nabla \tilde{u}) I\right]+\frac{2}{3} \bar{\rho} \tilde{k} I
$$

where, $\vartheta_{T}$ is the turbulent kinematic viscosity, if dissipation rate is $\tilde{\varepsilon}$ then,

$$
\vartheta_{T}=C_{\mu} \frac{\tilde{k}^{2}}{\tilde{\varepsilon}}
$$

$\tilde{k}$ is the turbulent kinetic energy, defined by,

$$
\tilde{k}=\frac{1}{2 \rho} \operatorname{trace}(\Gamma)=\frac{1}{2} \overline{u^{\prime \prime} u^{\prime \prime}}
$$

$C_{\mu}$ is a model constant that varies in different turbulence model formulations.

The turbulent flux term in the species transport equation is modeled as, $\boldsymbol{\varphi}=\bar{\rho} D_{T} \nabla \bar{y}_{k}$, where $D_{T}$ is the turbulent diffusivity.

Similarly, turbulent flux term

$$
H=-\lambda \nabla \bar{T}-\bar{\rho} D_{T} \sum_{k} \tilde{h}_{k} \nabla \bar{y}_{k}
$$

where $\bar{y}_{k}$ is the turbulent conductivity and is related to the turbulent thermal diffusivity $\alpha_{T}$ and heat capacity $C_{p}$ by $\lambda_{T}=$ $\bar{\rho} C_{p} \alpha_{T}$

The turbulent mass and thermal diffusivity are related to the turbulent viscosity by,

$$
\begin{aligned}
& D_{T}=\frac{\vartheta_{T}}{S_{C_{T}}} \\
& \alpha_{T}=\frac{\vartheta_{T}}{P_{r_{T}}}
\end{aligned}
$$

where, $S_{C_{T}}$ and $P_{r_{T}}$ are the turbulent Schmidt and Prandtl numbers, respectively.

\subsection{Geometry and mesh generation}

In case of diesel engine with equally spaced multi-hole injector, properties such as injection pressure, temperature, air-fuel mixture homogeneity or mixture concentration, combustion process etc. are considered identical with respect to each hole in the injector and the corresponding spray.

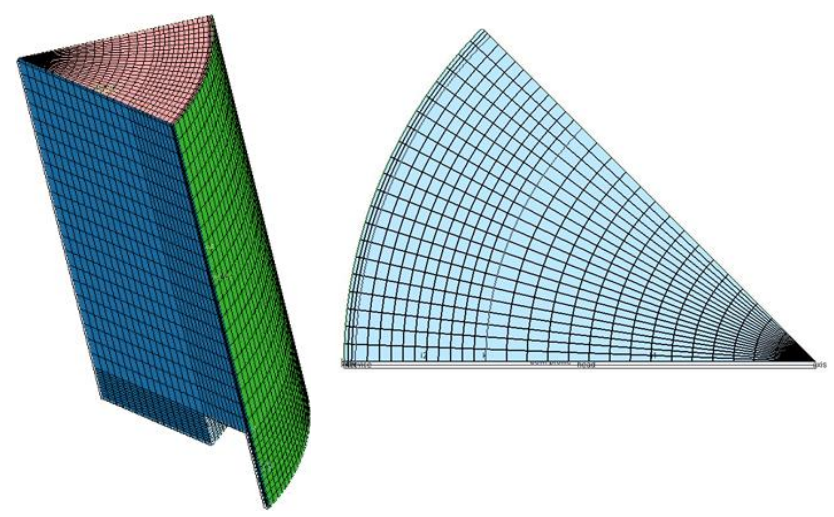

Fig. $1 \mathrm{~A} 45^{\circ}$ sector mesh for modeling diesel engine.

Therefore, the combustion chamber inside the engine cylinder is thought to be symmetrical with respect to each nozzlehole in the injector. As a consequence, an advantage can be readily obtained by simulating a certain section of geometry instead of considering whole engine geometry for calculation. For example, an eight-hole injector allows simulation using a $45^{\circ}$ sector $\left(360^{\circ} / 8\right)$. In the current study, for computational domain and mesh generation, a sector of $45^{\circ}$ angle with periodic boundary conditions applied at the periodic faces of the sector is considered instead of using the whole geometry of the engine in order to reduce computational cost without comprising the accuracy (Fig. 1).

Table 1 Engine specifications and operating conditions

\begin{tabular}{lc}
\hline Engine base type & Cummins N-14, DI diesel \\
\hline Number of cylinders & 1 \\
\hline Cycle & 4 -stroke \\
\hline Number of intake valves & 2 \\
\hline Number of exhaust valves & 1 \\
\hline Combustion chamber & Quiescent, direct injection \\
\hline Squish & $0.56 \mathrm{~cm}$ \\
\hline Bore & $13.97 \mathrm{~cm}$ \\
\hline Stroke & $16.02(\mathrm{CR}=15), 16.21$ \\
\hline Range of compression & $15: 1,18: 1,21: 1$ \\
ratio & $9.79 \times 1.55 \mathrm{~cm}$ \\
\hline Bowl width x depth & $30.2 \mathrm{~cm}$ \\
\hline Connecting rod length & $1200 \mathrm{rpm}$ \\
\hline Engine Speed & $0.6-1.2$ \\
\hline Range of equivalence ratio & actuated \\
\hline Fuel injector type & 8, equally spaced \\
\hline Number of holes & $3.02 \times 10^{-4} \mathrm{~cm}{ }^{2}$ \\
\hline Nozzle orifice area & $-22^{0}[$ After TDC] \\
\hline Start of Injection (SOI) & $368.0 \mathrm{~K}$ \\
\hline Inflow Droplet & 0.7 \\
\hline Temperature & \\
\hline Discharge Coefficient & \\
\hline
\end{tabular}


A single cylinder DI diesel engine based on a Cummins Nseries production engine has been modelled by using ANSYS Forte CFD simulation software. Details of the engine is available in Refs. [15],[16]. The engine specifications and operating conditions are given in Table 1 .

\subsection{Fuel chemistry and sub-models}

For specifying the chemical reaction mechanism for fuel combustion ANSYS Forte supports the industry standard CHEMKIN format. A reduced n-heptane mechanism that can be used to represent the diesel fuel under conventional diesel-engine combustion conditions and available in fuel library of ANSYS Forte is added to the chemistry model in the CFD code to simulate the combustion of diesel fuel. Some other important CFD sub models used in this simulation work are shown in Table 2.

Table 2 CFD Sub-models

\begin{tabular}{cc}
\hline Turbulence model & RNG $k-\varepsilon$ model \\
\hline Droplet breakup model & KH-RT model \\
\hline Combustion model & $\begin{array}{c}\text { Mixing controlled combustion } \\
\text { (MCC) }\end{array}$ \\
\hline Fuel chemistry model & n-heptane reduced mechanism \\
\hline Soot model & Two-step semi-empirical model \\
\hline $\begin{array}{c}\text { NOx formation } \\
\text { mechanism }\end{array}$ & Zeldovich mechanism \\
\hline
\end{tabular}

\subsection{Initial and boundary conditions}

The initial conditions in the engine simulations are presented in Table 3. These values are utilized for cases with different diesel injection timings and gasoline/diesel ratio. Law of the Wall model is specified for piston, head and liner which can capture wall boundary layer effects more accurately for boundary layers that are thinner than the mesh size. For incylinder engine simulations, the turbulent law-of-the-wall velocity condition and fixed temperature walls are usually employed.

Table 3 Initial conditions

\begin{tabular}{cc}
\hline Parameters & Value \\
\hline Intake Valve Closing & $165^{\circ}$ before TDC \\
\hline Exhaust Valve Open & $125^{\circ}$ after TDC \\
\hline Temperature at Inlet Valve Closing & $362 \mathrm{~K}$ \\
\hline Pressure at Inlet Valve Closing & $2.215 \mathrm{bar}$ \\
\hline Turbulent Kinetic Energy & $10,000 \mathrm{~cm}^{2} / \mathrm{sec}^{2}$ \\
\hline Turbulent Length Scale $(\mathrm{cm})$ & 1.0 \\
\hline Initial Swirl Ratio & 0.5 \\
\hline Initial Swirl Profile Factor & 3.11 \\
\hline
\end{tabular}

Table 4 Boundary conditions

\begin{tabular}{cc}
\hline Periodicity & 45 degree \\
\hline Wall model & Law of the wall \\
\hline Piston Temperature & $500 \mathrm{~K}$ \\
\hline Head Temperature & $470 \mathrm{~K}$ \\
\hline Line Temperature & $420 \mathrm{~K}$ \\
\hline
\end{tabular}

\section{Results and discussion}

3.1 Effect of compression ratio on combustion characteristics:

For diesel engines, the engine combustion is often simulated from intake valve closure (IVC) to exhaust valve opening (EVO), rather than modeling the full air intake or exhaust flow processes involving the intake and exhaust ports, respectively. This is usually a reasonable approximation since the gas in the cylinder at IVC is a relatively homogeneous mixture of air and exhaust gas (due to internal residual or from exhaust-gas recycling), prior to fuel injection. Here, in this study only a part of the engine operation, namely, in between IVC (i.e. 165 degree before TDC) to EVO (i.e. 125 degree after TDC) is simulated for the desired investigations.

Fig. 2 show the combustion characteristics of diesel in terms of in-cylinder pressure, temperature and apparent heat release rate $(\mathrm{AHH})$ for compression ratio of 15,18 and 21 . Both lean mixture with equivalence ratio, $\phi=0.8$ and rich mixture with equivalence ratio, $\phi=1.2$ are considered to analyse the effect of fuel concentration. It is observed that peak in-cylinder pressure, pressure rise rate, peak in-cylinder temperature, rate of temperature rise and heat release rate, all increase with compression ratio for both lean and rich mixtures. It is well known that, in CI engine prior to fuel injection both air temperature inside the cylinder and cylinder wall (including head, liner and piston top) temperature will be greater for higher compression ratio. This high temperature increases the mixture reactivity, and rate of mixing of fuel with air, causing rapid combustion of fuel that lead to steeper heat release rate, incylinder pressure and temperature. Among the three compression ratios, $\mathrm{CR}=15, \mathrm{CR}=18$ and $\mathrm{CR}=21$; both peak in-cylinder pressure and peak in heat release are close to TDC for $\mathrm{CR}=18$. It is desirable to have both peak in-cylinder pressure and peak in heat release nearer or closes to TDC as much as possible because these characteristics will lead to maximum engine power or torque. Therefore, it could be concluded that, in terms of combustion characteristics, compression ratio, $\mathrm{CR}=18$ is the optimum one. 

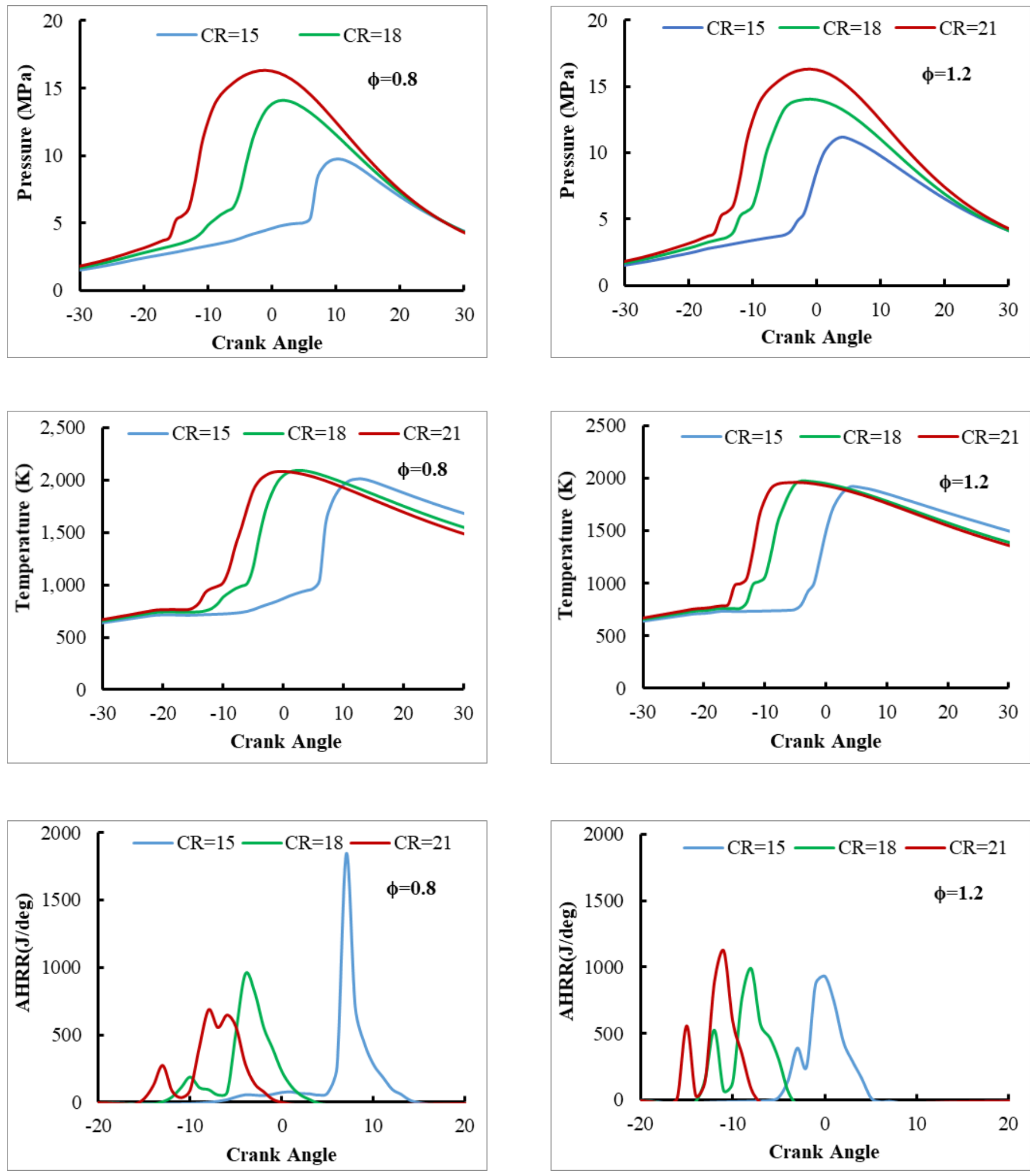

Fig. 2 In-cylinder Pressure, Temperature and Apparent Heat Release Rate (AHRR) Vs Crank angle at different equivalence ratio and compression ratio (for $\mathrm{CR}=15, \mathrm{CR}=18$ and $\mathrm{CR}=21$ ) 
After start of injection (SOI) of fuel, the time delay up to start the combustion (SOC) is termed as ignition delay which can be subdivided into physical delay and chemical delay. The higher temperature due to high compression ratio will facilitate atomization, vaporization and mixing of fuel with entraining air inside the combustion chamber, thereby decreasing physical delay. On the other hand, chemical delay also become shorter as high temperature accelerate the pre-flame reactions and make the air-fuel mixture ready for autoignition. Ignition delay becomes shorter with compression ratio over a range of equivalence ratio as depicted in Fig. 3. For compression ratio beyond $\mathrm{CR}=16$, rich mixture shows lower ignition delay compared to lean mixture. At lower compression ratio, for example $\mathrm{CR}=15$, it takes around $17 \sim 19 \mathrm{deg}$. of crank angle (CA) after SOI at $22.5^{\circ}$ before top dead center, TDC $\left(0^{0}\right.$ crank angle represents TDC). This is because in-cylinder temperature is not sufficiently high for atomization, vaporization, mixing of fuel with air, and preflame reactions to occur immediately after the fuel injection.

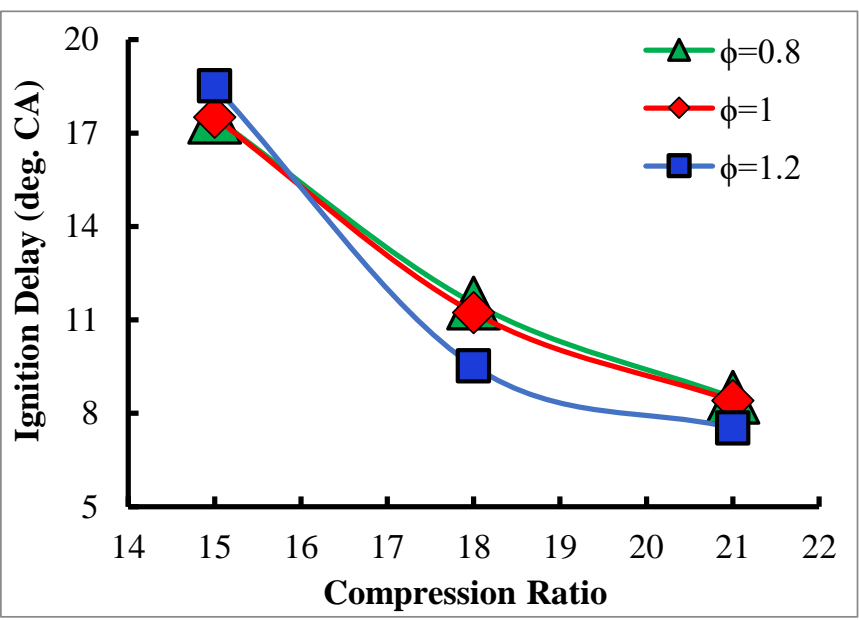

Fig. 3 Ignition delay as function of compression ratio for different equivalence ratios

\subsection{Effect of compression ratio on emission characteristics:}

It is evident from Fig. 4 that diesel engine NOx emission increases for relatively higher compression ratio. Previously it is seen that higher compression ratio causes higher pressure and temperature inside the cylinder. At high temperature, the nitrogen of the air can react with oxygen and forms various nitrogen oxides e.g. nitric oxide (NO) and nitrogen dioxide (NO2). According to thermal mechanism (commonly known as Zeldovich mechanism) temperature and oxygen concentration are the dominant factors in NOx formation; and it is found to increase exponentially with in-cylinder temperature [1]. This mechanism is highly sensitive to temperature not only because of the high activation energy of reaction but also as a result of the rapidly increasing oxygen atoms concentration in flames with increasing temperature [17]. Fig. 4 clearly demonstrates that for lean mixture with equivalence ratio, $\phi=0.8$, the exhaust emission of NOx is relatively higher but combustion of rich mixture $(\phi$ $=1.2$ ), reduces NOx emission drastically. As combustion is started earlier with higher compression ratio, therefore, emission of $\mathrm{CO}$ is seen to emit earlier in case of $\mathrm{CR}=21$ and $\mathrm{CR}=18$ compared to $\mathrm{CR}=15$ as shown in the Fig. 4 . Besides, introducing relatively higher amount of diesel fuel $(\phi=1.2)$, results in more $\mathrm{CO}$ emission compared to lean mixture with equivalence ratio, $\phi$ $=0.8$ which indicates incomplete combustion is more pronounced in case of combustion of rich mixture. Unburnt hydrocarbon emission is observed more in lower compression ratio, $\mathrm{CR}=15$ as a result of poor oxidation associated with lower in-cylinder temperature.

\subsection{Effect of equivalence ratio on combustion characteristics:}

For diesel engines, fuel concentration plays a vital role on combustion performance in terms of in-cylinder pressure, temperature and apparent heat release rate (AHRR). Fig. 5 illustrates that for fuel rich mixture, combustion of diesel fuel results in faster rate of pressure rise. As more fuel is injected for $\phi=1.0$ and 1.2 , compared to lean mixture, $\phi=0.6$ to 0.8 , therefore, a combustible mixture is readily formed in the combustion chamber and autoignition of fuel-air mixture occurs earlier. Though energy supplied is greater for comparatively rich mixture but combustion temperature is found to be lower for $\phi$ $=1.0$ and 1.2 , compared to lean mixture, $\phi=0.6$ to 0.8 . This might be attributed to the fact that even after autoignition of fuel-air, the injection of diesel fuel continues to occur directly in burning zone; as a consequence, a portion of the heat of combustion is absorbed by newly injected fuel droplets before vaporization. The highest combustion temperature is observed for $\phi=0.7$ and $\phi=0.8$. In addition, both peak in-cylinder pressure and peak in heat release are close to TDC for $\phi=0.7$ and $\phi=0.8$, which will lead to maximum power or torque. 

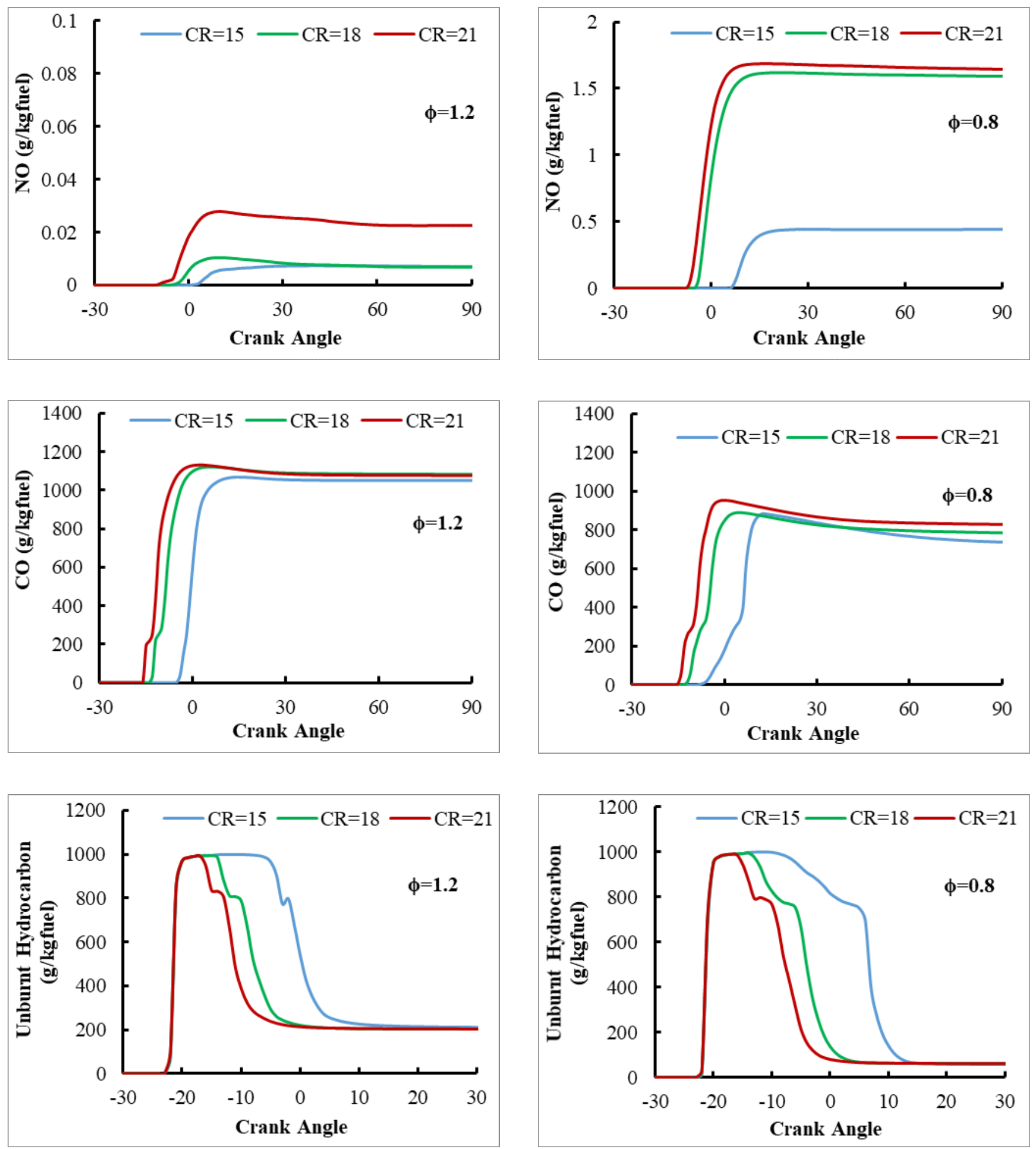

Fig. 4 Emission of $\mathrm{NO}_{\mathrm{x}}, \mathrm{CO}$ and Unburnt Hydrocarbon Vs Crank angle at different equivalence ratio and compression ratio (for $\mathrm{CR}=15, \mathrm{CR}=18$ and $\mathrm{CR}=21$ ) 

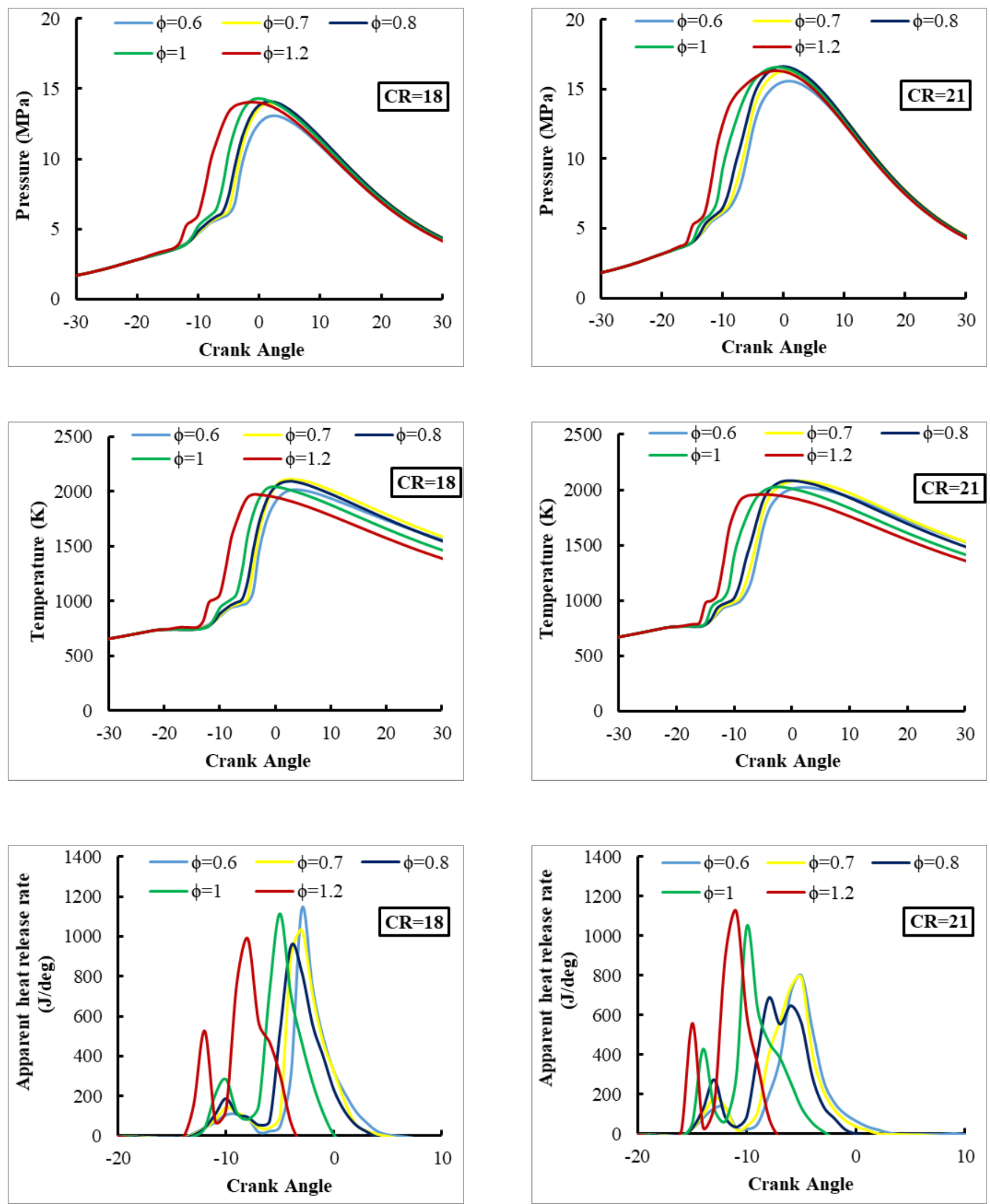

Fig. 5 In-cylinder Pressure, Temperature and Apparent Heat Release Rate (AHRR) Vs Crank angle over a range of equivalence ratio and compression ratio 


\subsection{Effect of equivalence ratio on emission characteristics:}

As mentioned before NOx formation inside the combustion chamber is highly temperature dependent process. It is also well known that lean burn strategy in diesel engine leads to high NOx emission. In the previous section, the in-cylinder temperature is found to be greater for equivalence ratio in the range of $\phi=0.6$ to $\phi=0.8$. In this numerical modelling, highest level of NOx emission is observed for lean combustion $(\phi=0.6$ and $\phi=0.7)$, as can be seen in Fig. 6. Whereas, for $\phi=1.0$ and $\phi=1.2$, due to low combustion temperature, NOx formation is suppressed significantly. On the other hand, comparative higher compression ratio, $\mathrm{CR}=21$ leads to more $\mathrm{NOx}$ emission than that for $\mathrm{CR}=18$.
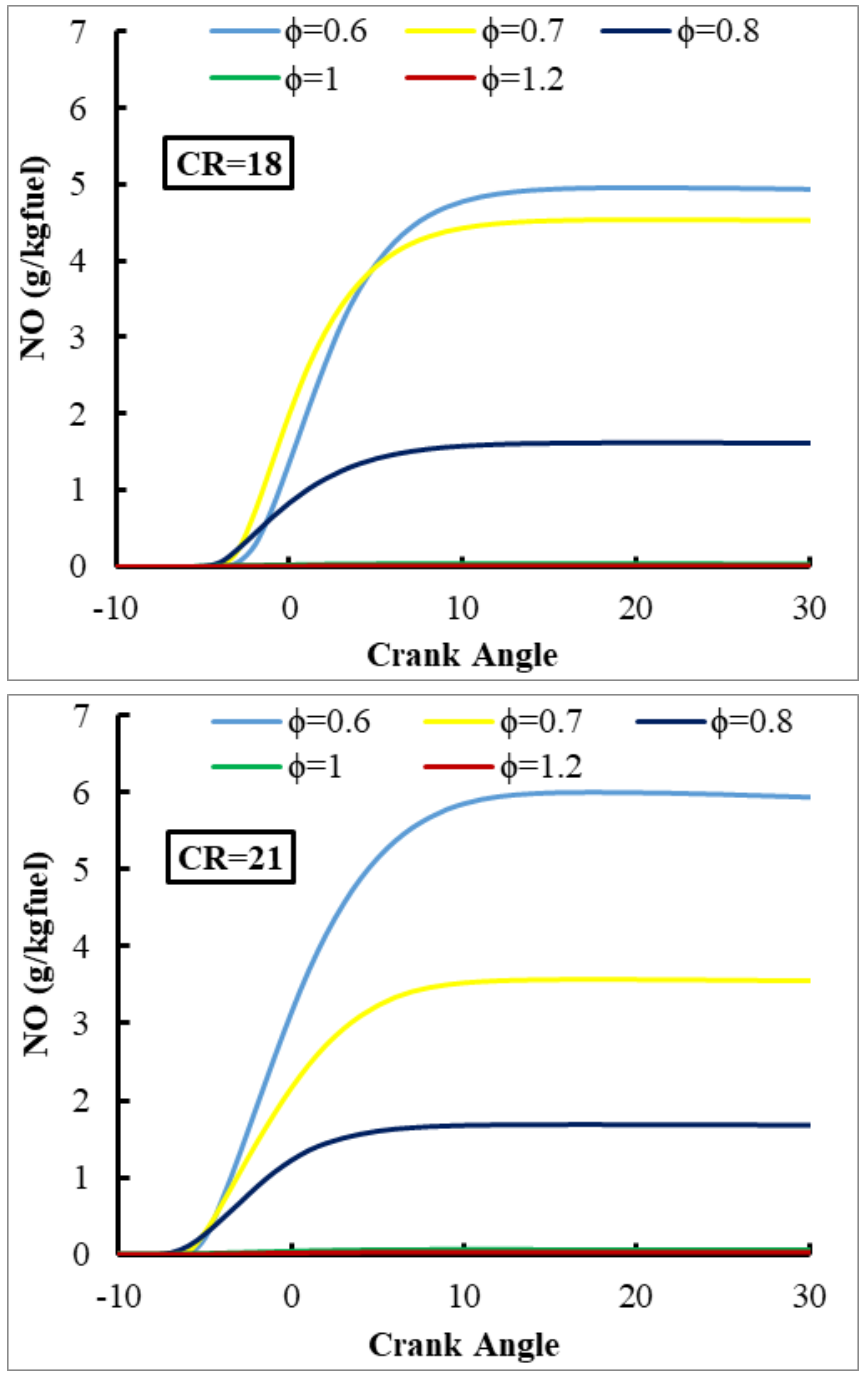

Fig. 6 Emission of $\mathrm{NO}_{\mathrm{x}} \mathrm{Vs}$ Crank angle for different equivalence ratio and compression ratio

\section{Conclusion}

In the present study, a diesel engine has been investigated through numerical modelling focusing primarily on the influences of equivalence ratio and compression ratio on combustion and emission characteristics. In order to reduce the computational cost and time, a sector mesh of $45^{\circ}$ angle with periodic boundary conditions applied at the periodic faces of the sector, is considered instead of using the whole engine geometry. CFD simulation are performed for a range of equivalence ratio varying from 0.6 to 1.2 and for three compression ratios namely, 15:1, 18:1 and 21:1. For combustion performance, in-cylinder pressure, temperature and apparent heat release rate (AHRR) are analysed whereas emission of NOx, $\mathrm{CO}$ and unburnt hydrocarbon are also quantified to highlight the emission performance. Based on the modeling results, the major conclusions that can be drawn are followings:

$>$ Rapid combustion occurs for higher compression ratios and improvement in combustion characteristics with compression ratio for both lean and rich mixtures is observed.

$>\quad$ Peak in-cylinder pressure and peak heat release nearer to TDC are achieved for compression ratio of 18:1 that could results in more engine torque.

$>$ For compression ratio beyond 16:1, rich mixture shows lower ignition delay compared to lean mixture. At lower compression ratio, in-cylinder temperature is not sufficiently high for atomization, vaporization, mixing of fuel with air, and preflame reactions to occur immediately after the fuel injection.

$>$ NOx emission in diesel engine increases due to higher pressure and temperature inside the cylinder associated with relatively higher compression ratio. Rich mixture results in more $\mathrm{CO}$ and unburnt hydrocarbon emission compared to lean mixture as result of incomplete combustion.

$>$ For fuel rich engine operation, a combustible mixture is readily formed in the combustion chamber and autoignition of fuel-air mixture occurs earlier.

\section{References}

[1] Heywood, J., 1988. Internal combustion engine fundamentals: McGraw-Hill Education.

[2] Prasad, R. and Bella, V.R., 2010. A review on diesel soot emission, its effect and control. Bulletin of Chemical Reaction Engineering \& Catalysis, 5(2), p.69.

[3] Tighe, C.J., Twigg, M.V., Hayhurst, A.N. and Dennis, J.S., 2012. The kinetics of oxidation of diesel soots by NO2. Combustion and flame, 159(1), pp.77-90.

[4] Sarvi, A., Lyyränen, J., Jokiniemi, J. and Zevenhoven, R., 2011. Particulate emissions from large-scale mediumspeed diesel engines: 1. Particle size distribution. Fuel processing technology, 92(10), pp.1855-1861.

[5] Demers, D. and Walters, G., 1999. Guide to exhaust emission control options. BAeSAME, Bristol.

[6] Payri, F., Bermúdez, V.R., Tormos, B. and Linares, W.G., 2009. Hydrocarbon emissions speciation in diesel and biodiesel exhausts. Atmospheric Environment, 43(6), pp.1273-1279.

[7] Hardy, W.L. and Reitz, R.D., 2006. A study of the effects of high EGR, high equivalence ratio, and mixing time on emissions levels in a heavy-duty diesel engine for PCCI combustion (No. 2006-01-0026). SAE Technical Paper.

[8] Jindal, S., Nandwana, B.P., Rathore, N.S. and Vashistha, V., 2010. Experimental investigation of the effect of compression ratio and injection pressure in a direct injection diesel engine running on Jatropha methyl ester. Applied thermal engineering, 30(5), pp.442-448. 
[9] Raheman, H. and Ghadge, S.V., 2008. Performance of diesel engine with biodiesel at varying compression ratio and ignition timing. Fuel, 87(12), pp.2659-2666.

[10] Zheng, J., Wang, J., Zhao, Z., Wang, D. and Huang, Z., 2019. Effect of equivalence ratio on combustion and emissions of a dual-fuel natural gas engine ignited with diesel. Applied Thermal Engineering, 146, pp.738-751.

[11] Montoya, J.P.G., Diaz, G.J.A. and Arrieta, A.A.A., 2018. Effect of equivalence ratio on knocking tendency in spark ignition engines fueled with fuel blends of biogas, natural gas, propane and hydrogen. International journal of hydrogen energy, 43(51), pp.23041-23049.

[12] Nam, D., 2000. How to reduce emission of nitrogen oxides [NOx] from marine diesel engines in relation to Annex VI of MARPOL 73/78.

[13] Jafarmadar, S., 2013. The Effect of Split Injection on the Combustion and Emissions in DI and IDI Diesel Engines.
Diesel Engine: Combustion, Emissions and Condition Monitoring, p.1.

[14] Taqizadeh, A., Jahanian, O. and Kani, S.I.P., 2020. Effects of equivalence and fuel ratios on combustion characteristics of an RCCI engine fueled with methane/nheptane blend. Journal of Thermal Analysis and Calorimetry, 139(4), pp.2541-2551.

[15] Dec, J.E., 1997. A conceptual model of DL diesel combustion based on laser-sheet imaging. SAE transactions, pp.1319-1348.

[16] Musculus, M.P., 2004. On the correlation between NOx emissions and the diesel premixed burn. SAE transactions, pp.631-651.

[17] Anetor, L., Odetunde, C. and Osakue, E.E., 2014. Computational analysis of the extended Zeldovich mechanism. Arabian journal for science and engineering, 39(11), pp.8287-8305. 